\title{
A STUDY OF THE RELATIONSHIP BETWEEN EATING HABITS AND BODY WEIGHT IN 13-16 YEAR OLD GIRLS
}

\author{
P. Dikova* \\ Department Heavy Athletics, Boxing, Fencing and Sport for All, Sector Sport for All, \\ National Sports Academy "Vassil Levski", Sofia, Bulgaria
}

\begin{abstract}
Nutrition problems in childhood and adolescence can be extremely serious and dangerous to health. In recent years, the Ministry of Health and the Ministry of Education and Science have taken actions which show their concern and desire for solving the problems, but the results of the studies carried out in this regard are still unsatisfactory. According to a WHO survey conducted in 2017, Bulgarian children are among the fattest in the world, occupying the $5^{\text {th }}$ place in the ranking. The published by the Ministry of Health data from a national survey conducted in 2010-2011 on students aged 6-19, showed that $30.2 \%$ of adolescents were overweight and $12.7 \%$ were obese.

Regular malnutrition or overeating is equally harmful to the growing body. Therefore, the building of rational and healthy eating habits from an early age is among the important components of general education.

This study presents a survey conducted on 239 girls aged 13-16. Their eating habits, body weight and BMI were analyzed. The results on these indicators allow us to draw a summarized picture of the group we examined.
\end{abstract}

Key words: nutrition, adolescents, BMI

\section{INTRODUCTION}

In recent years, serious attention to the nutrition of adolescents has been observed. A large number of studies have been carried out and subsequent analyzes of their results arouse disturbance. Serious gaps have been identified in the quality and quantity of the foods consumed in childhood and adolescence. The energy balance is disturbed, which leads to nutrition disorders in both directions. In addition to malnutrition, there is a very high percentage of overweight boys and girls. According to a WHO survey conducted in 2017, Bulgarian children are among the fattest in the world, taking the $5^{\text {th }}$ place in their ranking (1). The results of the national survey 2010-2011 on students aged 6 to 19 years are not different, revealing that $30.2 \%$ of

\footnotetext{
*Correspondence to: Petia Dikova, National Sports Academy "Vassil Levski”, Department Heavy athletics, boxing, fencing and sport for all, Sector Sport for all, 1700, Sofia, Bulgaria, Studentski grad, 21, Acad. Stefan Mladenov str., Email: petiamilanova@gmail.com, GSM: $+359893396470$
}

adolescents are overweight and $12.7 \%$ of the persons surveyed took place in the obese group. The generalized conclusion of the analysts is that "an alarming trend of increasing obesity in children in Bulgaria is established" (2).

The nutrition problems in childhood and adolescence are directly related to weight, body mass index (BMI) and overall lifestyle. Therefore, there is no need for permanent studies of different age groups are needed in order to contribute update adolescents' status, for validation or rejection their nutrition habits, and improve their health culture in nutrition and nutrients (3-6).

\section{METHODOLOGY}

Our survey of 239 girls in the 13-16 age range provided us the opportunity to analyze their nutrition habits and self-assessment on their body weight.

The questionnaire contained the following questions:

1. How old are you? 
2. What is your height (in $\mathrm{cm}$ )?

3. What is your weight (in $\mathrm{kg}$ )?

4. How would you describe your weight?

a) much below normal; b) slightly below normal; c) normal; d) slightly overweight; e) excessive overweight.

5. In your opinion, do you eat healthy? a) Yes;

b) No; c) sometimes

6. What does your menu most often contain?

a) dry food, sandwiches; b) soups, cooked meals; c) fruits, vegetables; d) fried foods; e) mostly chips, salutes, croissants, waffles, etc.; f) mostly patties, donuts, muffins, etc.; g) homemade sweets, cupcakes, creams and more.

\section{RESULTS AND ANALYSIS}

The data from the questionnaires were subjected to mathematical and statistical processing (7). Based on the results of the variation analysis, we found out that the study groups were highly homogeneous in terms of age, height and BMI and completely heterogeneous in body mass indicator.

The cross-group analysis of the indicators highlighted some specificities that are valid for all. They are mostly observed in height and body weight values, where the range is very large. For the indicator "Height", the biggest differences between the minimum and maximum dimensions are for girls 13 and 14year-old. As the age advances, this difference diminishes and for 16-year-old girls is only 19 $\mathrm{cm}$. The differences between the lowest and the highest values for the Body Weight indicator are in the range of $26-40 \mathrm{~kg}$, with the largest spread is at 14-year-olds, followed by 16-year-old girls (Figure 1). Despite these deviations, a detailed analysis of these two indicators leads us to indirect conclusion that girls' physical development is normal and we generally do not observe accelerants and retardants, although the existence of isolated cases.

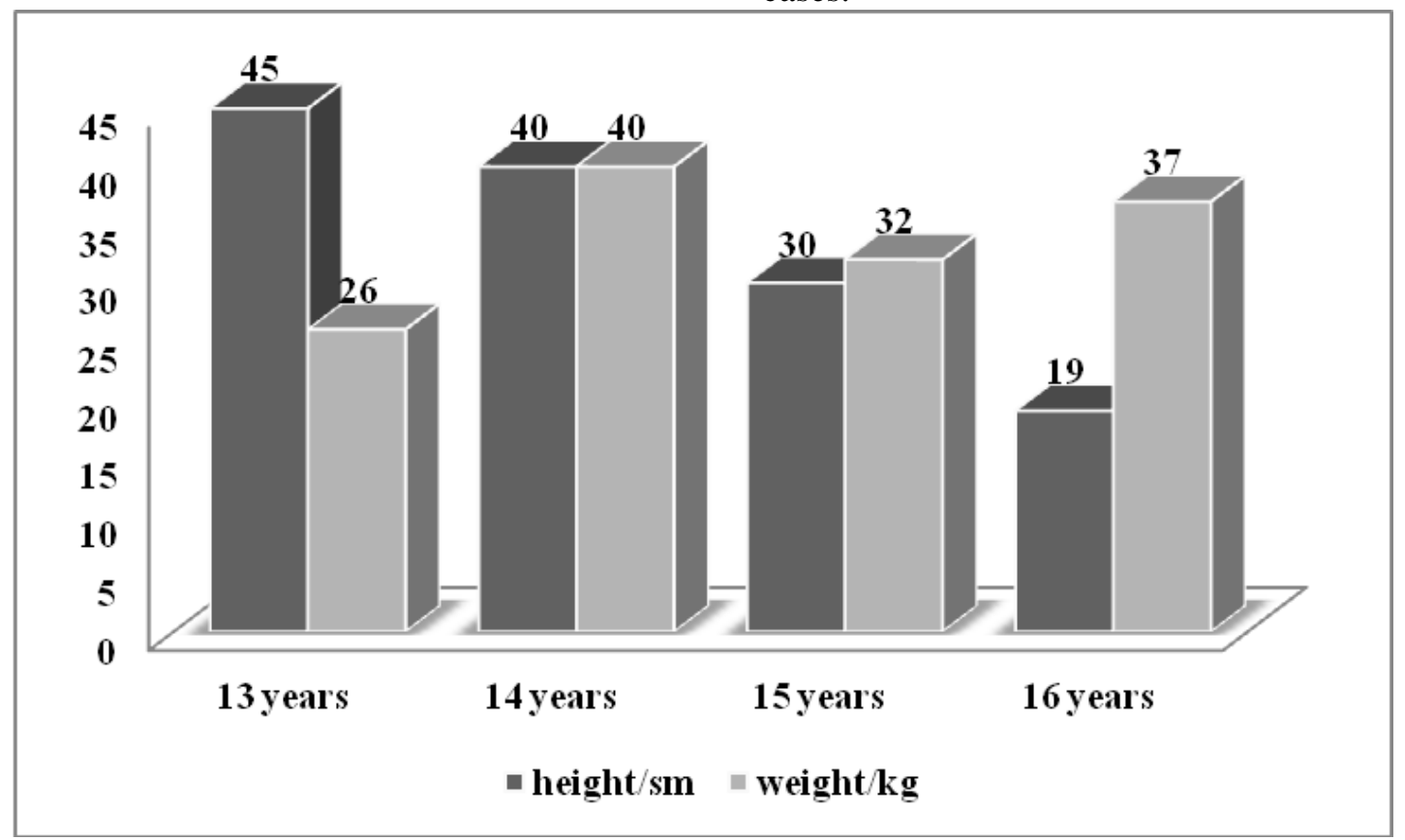

Figure 1. Absolute range values for height and weight

Referenced to body mass index, the calculated average values indicate underweight for 13-14 year old girls, and weight in the normal range for 15-16-year-olds (Figure 2). We can assume that there are irrational eating habits at this age, which is also supported by their answers to questions 5 and 6 in the questionnaire. In this regard, the selfassessment of the female students surveyed in response to the question "How would you describe your weight?" differs from the actual status. Only one girl at the age of 15 thinks that her body weight is much below normal. Slightly below the norm are self-assessed - 4 girls of age 13-year-old, 2 of 14-year-old, 3 of 15 -year-old and 7 of 16 year-old. A total of 12 girls of the studied ages were identify themselves as very overweight, and 29 (12.7\%) girls as slightly overweight, with the largest share of 13 -year-olds - $6.3 \%$ of the total aggregation (Figure 3). 


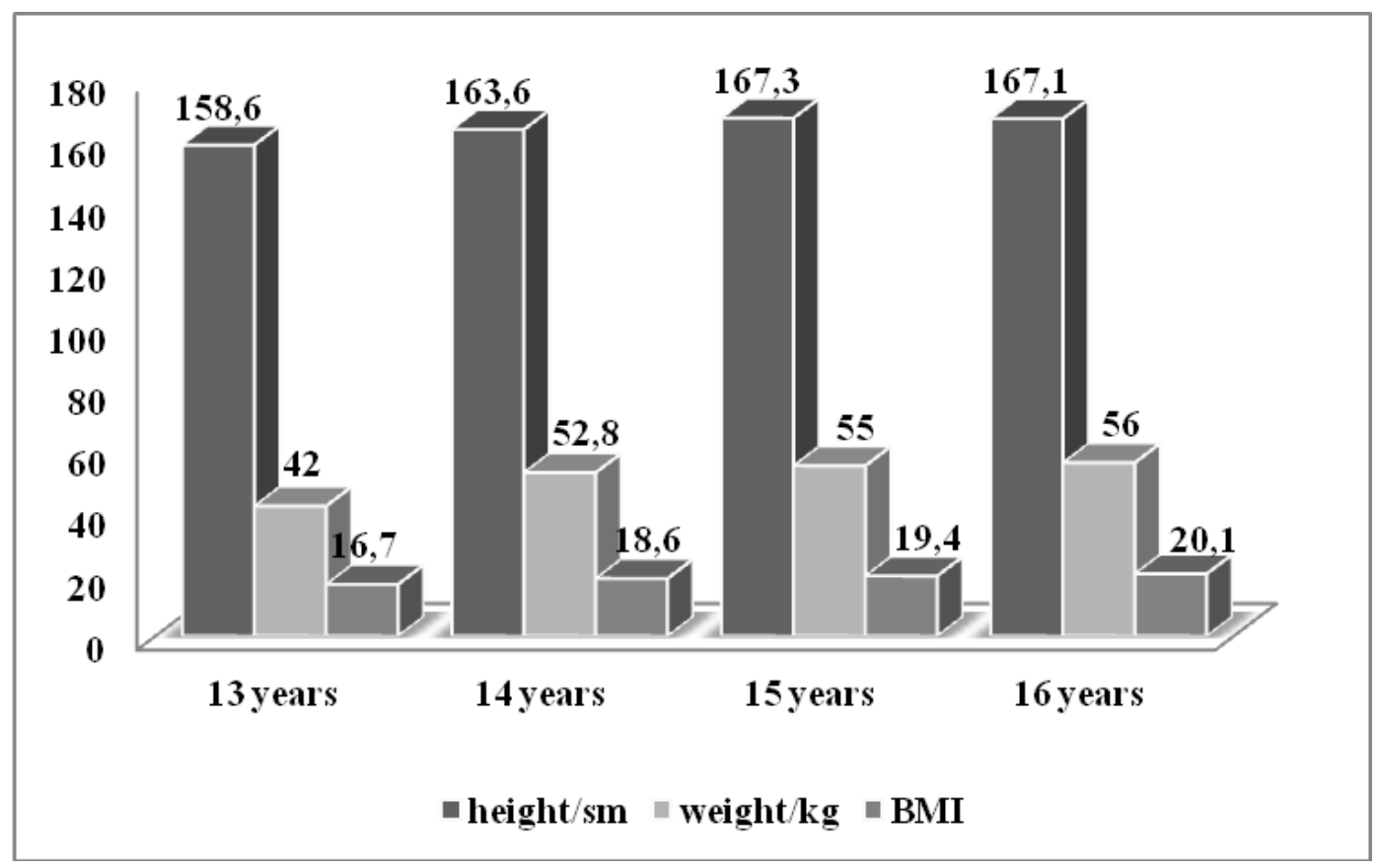

Figure 2. Age distribution of average values of height, weight and BMI

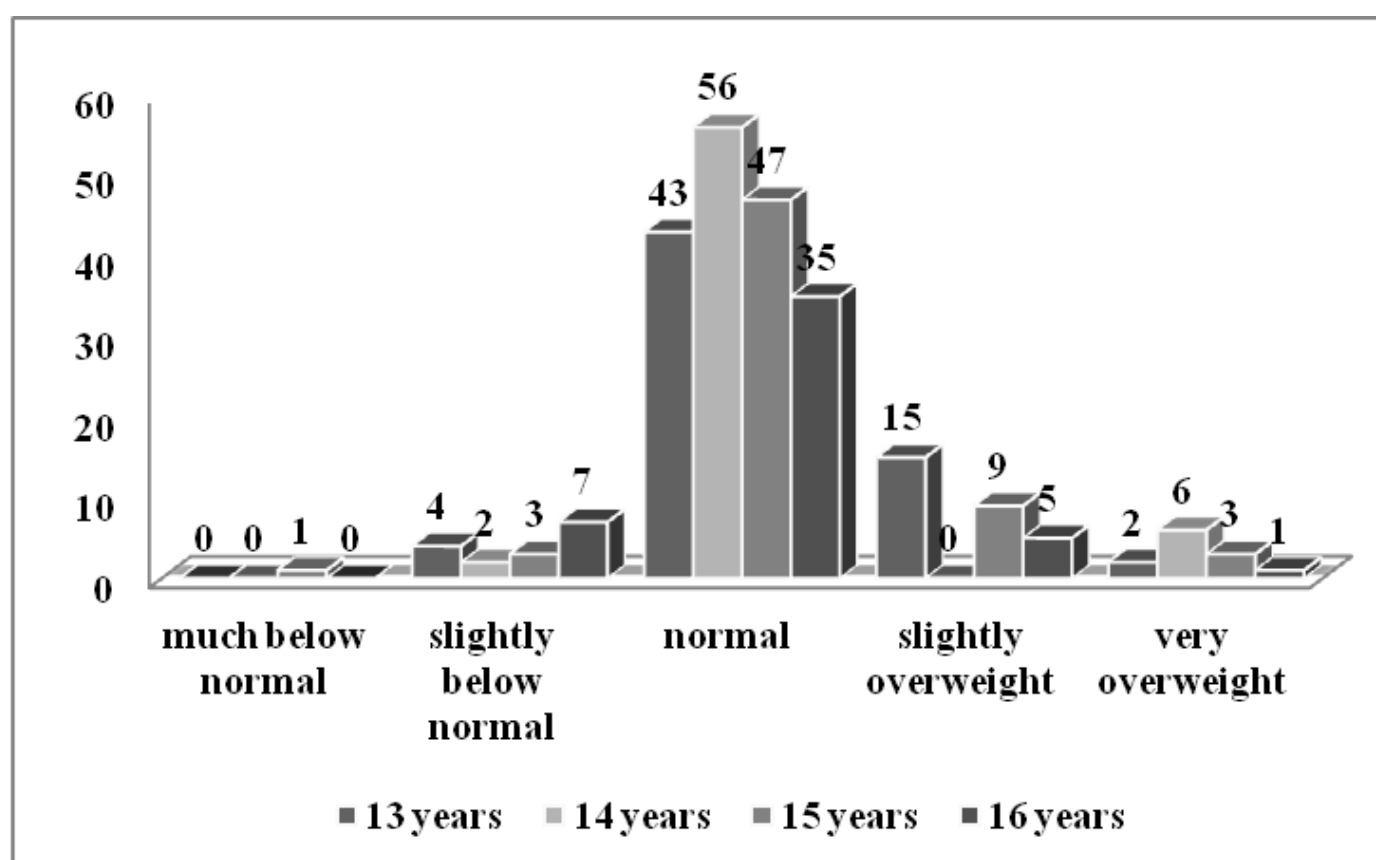

Figure 3. Answers to the question "How would you describe your weight?" in absolute values

Among the girls surveyed, the percentage with the highest share was the claim for normal weight $-75.7 \%$. The age distribution is as follows: 13 -year-olds - 67.2\%; 14- year -olds $87.5 \%$; 15 -year-olds $-74.6 \%$ and 16 years $72.9 \%$. Normal and slightly overweight cases predominate.

According to a study among 17-19-year-old female students, conducted by L. Kasabova, 2019, this trend remains the same with increasing the age. The highest relative share is for girls with normal body weight (8).

We all know that healthy nutrition should be varied in content, balanced regarding to the nutrients taken, with a particular diet, which is recommended to include 3 main meals and 2 snacks a day. In our opinion, the knowledge of 13-16-year-old female students about nutrition in all its diversity is insufficient and incomplete, which is why we accept with some uncertainty their answers to the question "Do you take healthy foods?" (Figure 4). 
DIKOVA P.

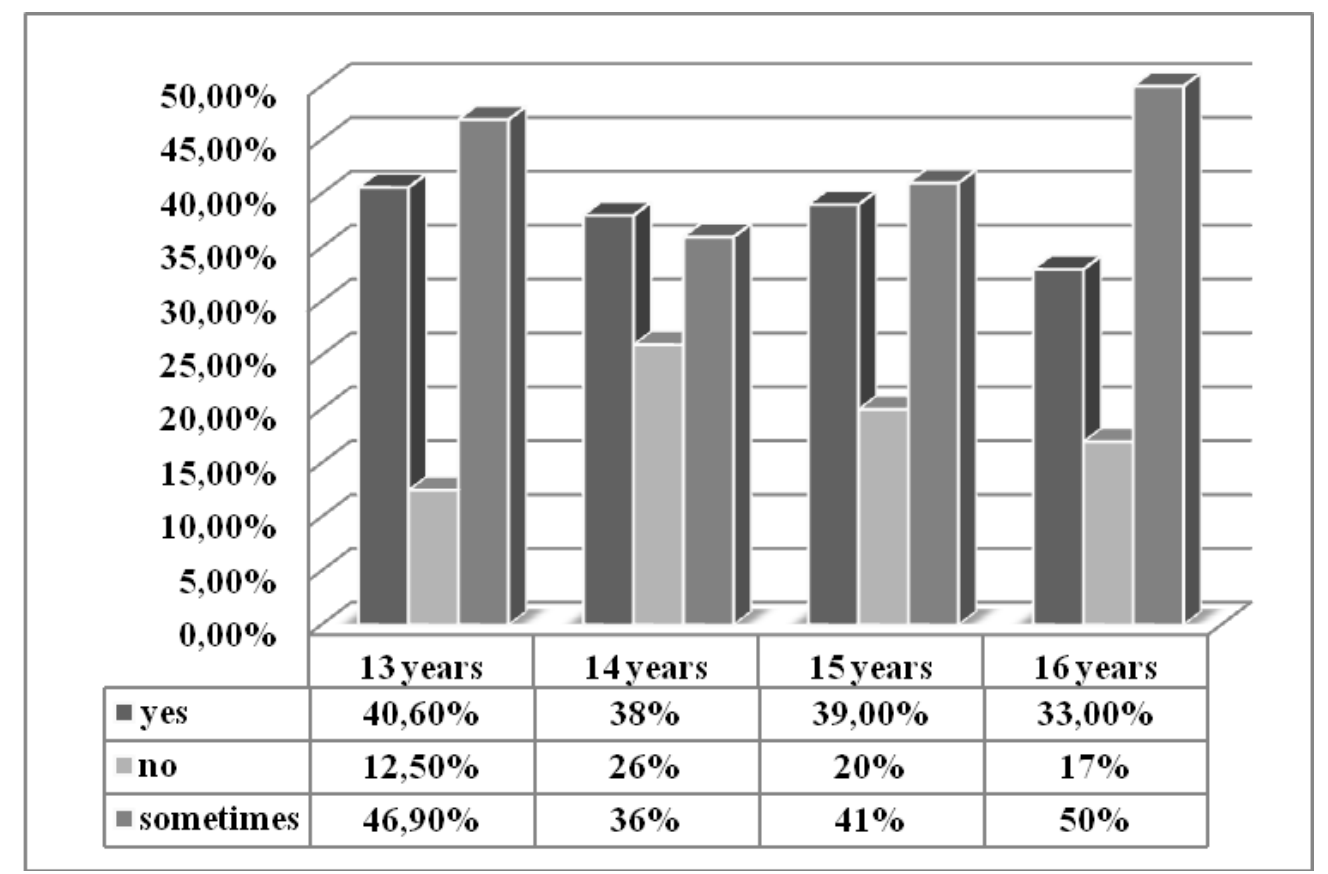

Figure 4. Percentage distribution of answers to the question "Do you think your nutrition is healthy?"

Approximately $1 / 3$ of the girls in the study age range responded positively, i.e. consider themselves eating healthy. Most of them point out that they sometimes eat healthily, and approximately $1 / 4$ of 14-15-year-old girls give a negative answer. In it we find the reason for the underweight of 13-14-year-old girls. Although the positive response of almost $40 \%$, we have doubts about its correctness. BMI determines them in the underweight group, with cases with a body mass index below 15 $\mathrm{kg} / \mathrm{m}^{2}$. In our view, this is an indicator of a lack of balanced and healthy nutrition.

A complete view of our group's nutrition habits gives us answers to the question "What does your menu most often contain?" Possible answers cover almost the entire palette of a variety of types of food. Preferences for soups, cooked meals, fruits and vegetables are prevalent. They are followed by fried foods and sandwiches (Figure 5). These results are satisfactory in their own right, but there is more to be achieved. Characteristic of this age are accelerated growth processes and increased physical activity, which are directly related to diet. Food is the "fuel" of the body and it must provide the energy needed to carry out the vital processes. Adolescent health depends on its quality and quantity.

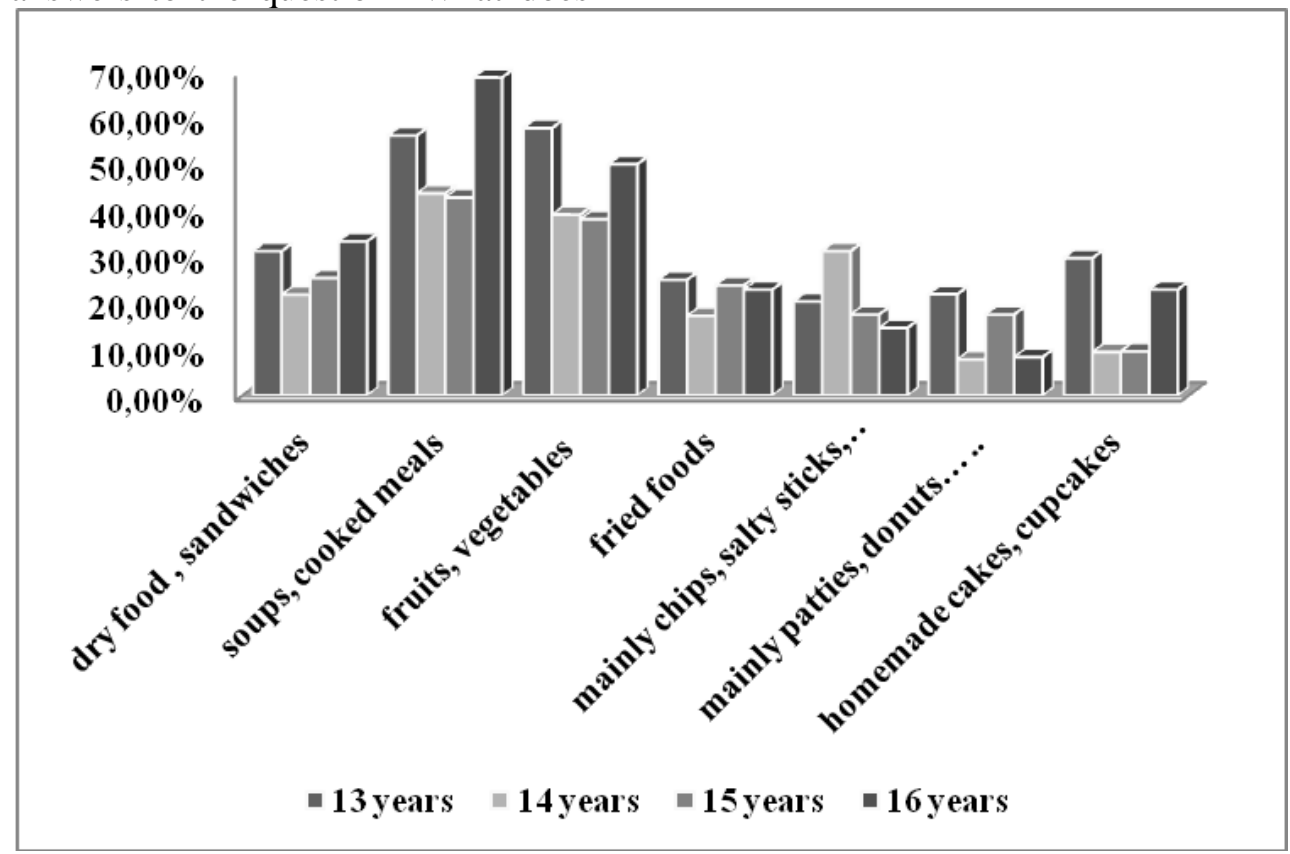

Figure 5. Answers to the question "What does your menu most often contain?" 
The least preferred food among the respondents is pasta and homemade cakes. An exception is 13-year-old girls, of whom nearly $1 / 3$ has indicated their preferences for them. It is satisfying that soups, cooked meals, fruits and vegetables are in the menu of the majority of the respondents at all ages. However, not a few prefer dry food and sandwiches, which is disturbing. More than $20 \%$ of all girls stated their preference and for fried foods, and at 14year-old girls $31.2 \%$ - for chips, salty sticks, waffles and more. The answers given to this question give us reason to believe that all the above mentioned foods are more or less present on the menu of 13-16-year-old girls.

\section{CONCLUSIONS}

The results of the questionnaire provide us the opportunity making the following summarized conclusions, with the proviso that they are not generally valid, but refer to girls aged 13-16year-old, who participated in our study.

1. There are no significant differences in the anthropometric indicators for the age groups 13-14-year-olds and 15-16-year-olds studied by us. The differences in height and weight give us fundament to define the development of the girls within the normal for their age.

2. There is a relatively accurate selfassessment for body weight.

3. In terms of food intake, we consider diversity, but we have no information of its quantity and quality. We suspect that at 13-14- year-old girls the intake of food is not sufficient.

\section{REFERENCES}

1. http://www.euro.who.int/en/healthtopics/disease-prevention/nutrition/ahealthy-lifestyle/body-mass-index-bmi (accessed 10 April 2020)

2. http://www.detskabolnica.com/index.php?o ption $=$ com_content \&view $=$ article $\& i d=29: 2$ 011-04-04-09-19-01\&catid=26:2011-0401-20-33-10\&Itemid=23 (accessed 10 April 2020)

3. Balabanski, L., Obesity - a health risk. Practical Pediatrics. 4/2003.

4. Gatseva, P., Frequency of overweight and obesity in adolescents and assessment of their knowledge of healthy eating. Scripta periodica. 10/2007.

5. Dimitrova, D., Nutrition and sports. NSA PRESS. S. 2014.

6. Milanova, P., Relationship between body weight and nutrition in adolescents. Sport \& Science, 5/2012.

7. Gigova, V., Statistical data processing and analysis. S. 2006.

8. Kasabova, L., Physical development and functional workability of the female students in the beginning of their study in the UNSS, International Scientific Conference "PEDAGOGICAL EDUCATION - TRADITIONS AND MODERNITY", Veliko Tarnovo, ed. I AND BI, pp.552-558, 2019. 